\title{
Pengukuran Kualitas Jaringan Internet Dengan Sinyal 3G Lte Pada STMIK Budi Darma Medan dengan Metode Quality Of Service (QoS)
}

\author{
${ }^{1)}$ Sony Bahagia Sinaga \\ AMIK STIEKOM Sumatera Utara, JI. A.H Nasution No. 19, Sumatera Utara, Indonesia \\ http://www.amikstiekomsu.ac.id , E-mail : sonybahagia@gmail.com \\ ${ }^{2)}$ Yasir Hasan \\ STMIK Budidarma, Jl. Sisingamangaraja No.338, Sumatera Utara, Indonesia \\ http://www.stmik-budidarma.ac.id, Email : dos.asmbd@gmail.com
}

\begin{abstract}
ABSTRAK
In today's age the internet needs are very important for communicating or looking for information. The longer the development of the internet network is increasingly widespread such as 1G, 2G, 3G and 4G technologies. Long Term Evolution (LTE) is a long-term radio evolution access network issued by the 3rd (Generation Partnership Project). To improve internet network services at STMIK Budidarma, testing and measurement are carried out using the Quality Of Service (QoS) method to determine the quality and power of data transfer. The Quality Of Service (QoS) method found on a TCP / IP network is one that focuses on allocating bandwidth within the internet network that flows fairly and as needed. The QoS method that relies on testing the process of delay time, latency time, packet request time and creating a network topology to reduce the risk that arises.
\end{abstract}

\section{Kata kunci : Internet, Sinyal, 3G LTE, Metode QoS}

\section{PENDAHULUAN}

Perkembangan teknologi informasi saat ini semakin maju dengan memunculkan teknologi baru yang sering kita sebut dengan teknologi internet. Menurut salah seorang pakar internet asal Indonesia, Onno W. Purbo menjelaskan bahwa internet dengan berbagai aplikasinya seperti Web, VolP, e-mail pada dasarnya merupakan media yang digunakan untuk mengefisiensikan proses komunikasi, sehingga internet seakan menjadi ikon di era globalisasi ini ${ }^{[1]}$. Bahkan teknologi internet saat ini telah digunakan dari kalangan anak - anak, remaja, hingga yang sudah dewasa, semua telah menggunakan internet, baik untuk jejaring sosial, pencarian informasi, maupun kebutuhan lainnya. Sebuah survei yang diselenggarakan Asosiasi Penyelenggara Jasa Internet Indonesia (APJSII) mengungkapkan bahwa jumlah pengguna internet di Indonesia tahun 2012 mencapai 63 juta orang atau 24,23 persen dari total populasi negeri ini, pada tahun 2013 meningkat 13 persen menjadi 71,19 juta orang, dan pada 2014 mencapai 107 juta orang yang menggunakan internet (Kompas.com). Sehingga tidak bisa dipungkiri lagi bahwa internet adalah salah satu kebutuhan bagi semua orang.
Internet (kependekan dari interconnectionnetworking) adalah seluruh jaringan komputer yang saling terhubung menggunakan standar sistem global Transmission Control Protocol/Internet Protocol Suite (TCP/IP) sebagai protokol pertukaran paket (packet switching communication protocol) untuk melayani miliaran pengguna di seluruh dunia. Rangkaian internet yang terbesar dinamakan Internet. Cara menghubungkan rangkaian dengan kaidah ini dinamakan internetworking ("antarjaringan"). Dengan banyaknya pengguna internet, untuk itu kualitas layanan internet yang diberikan oleh suatu Internet Service Provider (ISP) harus bagus untuk memberi pelayanan internet kepada para pengguna fasilitas internet. Namun demikian sebagian besar pengguna internet belum tahu apakah kualitas layanan internet yang mereka peroleh dari Internet Service Provider langganan mereka sudah baik atau belum.

Adapun perumusan masalah yang akan dibahas dalam penelitian ini antara lain :

1. Bagaimana pengukuran layanan jaringan internet pada STMIK Budi Darma?

2. Bagaimana melakukan pengujian layanan jaringan internet $3 G$ pada STMIK Budi Darma? 
Penelitian ini akan menghasilkan suatu kecepatan internet dan layanan internet intuk sinyal 3G. Adapun rincian urgensi dari penelitian ini adalah :

1. Mempermudah bagi pemakai (konsumen) layanan jaringan internet kualitas sinyal 3G.

2. Mengetahui kelemahan dari sinyal $3 G$.

3. Dapat memonitoring kecepatan data yang digunakan pada sinyal $3 \mathrm{G}$.

\section{LANDASAN TEORI}

\subsection{Analisa}

Analisa atau analisis adalah suatu proses mengurai konsep ke dalam bagian bagian yang lebih sederhana, sedemikian rupa sehingga struktur logisnya menjadi jelas. Analisa atau analisis merupakan suatu proses mengurai suatu hal menjadi berbagai unsur yang terpisah untuk memahami sifat, hubungan, dan peranan masing-masing unsur. Analisis secara umum sering juga di sebut sebagai pembagian.

Dalam logika, analisis atau pembagian berarti pemecah-belahan atau penguraian secara jelas berbeda ke bagianbagian dari suatu keseluruhan. Bagian dan keseluruhan selalu berhubungan. Suatu keseluruhan adalah terdiri atas bagianbagian. Oleh karena itu, sehingga dapat diuraikan. Rahadi (2010,p.113) Analisa data adalah pengelompokkan, membuat suatu urutan, memanipulasi serta menyingkatan data sehingga mudah untuk di baca. Langkah pertama dalam analisa adalah membagi data atas Kategori Kategori atau kata lain bagian - bagian.

\subsection{Quality Of Service (QoS)}

QoS merupakan kependekan dari Quality of Service. Dalam buku Quality of Service yang ditulis oleh Paul Ferguson, didefinisikan bahwa QoS adalah suatu pengukuran tentang seberapa baik jaringan dan merupakan suatu usaha untuk mendefinisikan karakteristik dan sifat dari suatu servis ${ }^{[2]}$.

QoS biasanya digunakan untuk mengukur sekumpulan atribut performansi yang telah dispesifikasikan dan biasanya diasosiasikan dengan suatu servis. Pada jaringan berbasis IP, IP QoS mengacu pada performansi dari paket-paket IP yang lewat melalui satu atau lebih jaringan. QoS didesain untuk membantu end user menjadi lebih produktif dengan memastikan bahwa dia mendapatkan performansi yang handal dari aplikasi-aplikasi berbasis jaringan. Dari segi networking, Quality of Service (Qos) mengacu kepada kemampuan memberikan pelayanan berbeda kepada lalu lintas jaringan dengan kelas-kelas yang berbeda. Tujuan akhir dari Quality of Service (QoS) adalah memberikan layanan jaringan yang lebih baik dan terencana dengan dedicated bandwidth dan latency yang terkontrol dan meningkatkan loss karakteristik., atau Qos adalah kemampuan dalam menjamin pengiriman arus data penting atau dengan kata lain kumpulan dari berbagai kumpulan dari berbagai kriteria performansi yang menentukan tingkat kepuasan suatu layanan ${ }^{[2]}$.

\subsection{Sinyal $4 G$ LTE}

4G adalah singkatan atau kepanjangan dari Fourth Generation yaitu generasi keempat dari standar teknologi komunikasi telepon selular. Jaringan 4G, diyakini memberikan banyak fitur dan nilai tambah dari 3G. Selain memiliki semua fasilitas $3 G$, transmisi data 4G diyakini mempunyai kecepatan transmisi berkisar antara 100 Mbps - 1 Gbps. Percakapan, internet, chatting, jejaring, permainan, video atau apa pun fitur yang ada di dalamnya dapat dinikmati lebih baik dari $3 \mathrm{G}^{[4]}$.

\section{METODE PENELITIAN}

Pendekatan yang digunakan dalam penelitian ini adalah metode grounded teori (Grounded Theory Approach) yaitu metode penelitian kualitatif yang menggunakan sejumlah prosedur sistematis guna mengembangkan teori dari kancah ${ }^{[3]}$. Pendekatan ini pertama kali disusun oleh dua orang sosiolog; Barney Glaser dan Anselm Strauss.

Penelitian ini tidak bertolak dari suatu teori atau untuk menguji teori (seperti paradigma penelitian kuantitatif), melainkan bertolak dari data menuju suatu teori. Pendekatan Grounded Theory merupakan metode ilmiah, karena prosedur kerjanya yang dirancang secara cermat sehingga memenuhi keriteria metode ilmiah. Keriteria dimaksud adalah adanya signifikansi, kesesuaian antara teori dan observasi, dapat digeneralisasikan, dapat diteliti ulang, adanya ketepatan dan ketelitian, serta bisa dibuktikan.

\section{HASIL DAN PEMBAHASAN}


Kabel Ethernet yang digunakanpun harus sesuai dengan kebutuhan, seperti kabel ethernet yang langsung terhubung ke router dan switch yang terdapat pada server, kabel Ethernet yang digunakan adalah kabel ethernet jenis UTP (Unshield Twisted Pair) kategori Cat 6.

Pemilihan penggunaan kabel kategori Cat 6 dikarenakan ukuran data yang lewat pada media kabel Ethernet tersebut besar. Sedangkan kabel ethernet yang digunakan pada radio di antena menggunakan kabel ethernet jenis STP (Shielded Twisted Pair) kategori Cat 5e, pemilihan penggunaan kabel STP karena digunakan di luar ruangan.

TABEL 1. Indeks Paramater QoS

\begin{tabular}{|c|c|c|}
\hline Nilai & $\begin{array}{c}\text { Persentase } \\
(\%)\end{array}$ & Indeks \\
\hline $3,8-4$ & $95-100$ & $\begin{array}{c}\text { Sangat } \\
\text { memuaskan }\end{array}$ \\
\hline $3-3,79$ & $75-94,75$ & Memuaskan \\
\hline $2-2,99$ & $50-74,75$ & $\begin{array}{c}\text { Kurang } \\
\text { memuaskan }\end{array}$ \\
\hline $1-1,99$ & $25-49,75$ & Jelek \\
\hline
\end{tabular}

TABEL 2. Performan Jaringan IP berdasarkan Packet Loss

\begin{tabular}{|c|c|c|}
\hline Kategori & Packet loss & Indeks \\
\hline $\begin{array}{c}\text { Sangat } \\
\text { Bagus }\end{array}$ & $0 \%$ & 4 \\
\hline Bagus & $3 \%$ & 3 \\
\hline Sedang & $15 \%$ & 2 \\
\hline Jelek & $25 \%$ & 1 \\
\hline
\end{tabular}

TABEL 3. Standarisasi Throughput

\begin{tabular}{|c|c|c|}
\hline Kategori & Throughput & Indeks \\
\hline $\begin{array}{c}\text { Sangat } \\
\text { Bagus }\end{array}$ & $100 \%$ & 4 \\
\hline Bagus & $75 \%$ & 3 \\
\hline Sedang & $50 \%$ & 2 \\
\hline Jelek & $<25 \%$ & 1 \\
\hline
\end{tabular}

TABEL 4. Standarisasi Delay (Latency)

\begin{tabular}{|c|c|c|}
\hline Latency & Besar Delay & Indeks \\
\hline $\begin{array}{c}\text { Sangat } \\
\text { Bagus }\end{array}$ & $<100 \mathrm{~ms}$ & 4 \\
\hline Bagus & $150-300 \mathrm{~ms}$ & 3 \\
\hline Sedang & $300-450 \mathrm{~ms}$ & 2 \\
\hline Jelek & $>450 \mathrm{~ms}$ & 1 \\
\hline
\end{tabular}

TABEL 5. Hasil Pengukuran total rata-rata bandwidth dan throughput

\begin{tabular}{|c|c|c|c|c|}
\hline \multirow{2}{*}{ Waktu } & \multirow{2}{*}{ Bandwidth } & \multicolumn{3}{|c|}{ Throughput (Mbps) } \\
\cline { 3 - 5 } & & Down & Up & $\begin{array}{c}\text { Down } \\
(\%)\end{array}$ \\
\hline
\end{tabular}

\begin{tabular}{|c|c|c|c|c|}
\hline Pagi & $1 \mathrm{Mbps}$ & 0,85 & 0,79 & 85 \\
\hline Siang & $1 \mathrm{Mbps}$ & 0,90 & 0,80 & 90 \\
\hline Sore & $1 \mathrm{Mbps}$ & 0,80 & 0,80 & 80 \\
\hline Malam & $1 \mathrm{Mbps}$ & 0,86 & 0,81 & 86 \\
\hline
\end{tabular}

TABEL 6. Hasil Pengukuran Delay Website Kompas.com

\begin{tabular}{|c|c|}
\hline Waktu & $\begin{array}{c}\text { Total Rata-rata delay }(\mathrm{ms}) \\
\text { kompas.com }\end{array}$ \\
\hline Pagi & 73 \\
\hline Siang & 68 \\
\hline Sore & 71 \\
\hline Malam & 80 \\
\hline
\end{tabular}

TABEL 7. Hasil Pengukuran Delay website bolanews.com

\begin{tabular}{|c|c|}
\hline Waktu & $\begin{array}{c}\text { Total Rata-rata delay }(\mathrm{ms}) \\
\text { kompas.com }\end{array}$ \\
\hline Pagi & 69 \\
\hline Siang & 78 \\
\hline Sore & 64 \\
\hline Malam & 80 \\
\hline
\end{tabular}

TABEL 8. Hasil Pengukuran packetloss website Facebook.com

\begin{tabular}{|l|c|c|c|c|}
\hline \multirow{2}{*}{ Hari/tangal } & \multicolumn{4}{|c|}{ Packetloss (\%) Facebook.com } \\
\cline { 2 - 5 } & Pagi & Siang & Sore & Malam \\
\hline $\begin{array}{l}\text { Senin, 6 } \\
\text { November } \\
2017\end{array}$ & 1 & 2 & 1 & 2 \\
\hline $\begin{array}{l}\text { Selasa, 7 } \\
\text { November } \\
2017\end{array}$ & 2 & 2 & 2 & 1 \\
\hline $\begin{array}{l}\text { Rabu, 8 } \\
\text { November } \\
2017 \text { Kas, 9 }\end{array}$ & 2 & 3 & 2 & 1 \\
\hline $\begin{array}{l}\text { Kamis, } \\
\text { November } \\
2017 \text { J 10 }\end{array}$ & 2 & 1 & 1 & 1 \\
\hline $\begin{array}{l}\text { Jumat, 10 } \\
\text { November } \\
2017\end{array}$ & 5 & 2 & 1 & 1 \\
\hline $\begin{array}{l}\text { Sabtu, 11 } \\
\text { November } \\
2017\end{array}$ & 2 & 3 & 1 & 1 \\
\hline
\end{tabular}

\section{KESIMPULAN}

Hasil monitoring bandwidth dan throughput pada klien Broadband Sistem antrian yang diterapkan pada jaringan internet pada STMIK Budi Darma adalah sistem antrian HTB (Hierarcichal Token Bucket).

\section{DAFTAR PUSTAKA}

1. Cahyana, dkk, 'Simulasi Pengukuran Quality Of Service pada Integritas Internet Protocol dan Asynchronous Transfer 
Mode dengan Multiprotocol Label Switching (MPLS), Departemen Teknik Elektro-Institut Teknologi Bandung.

2. Kamarullah, A. Hafiz 2009, 'Penerapan Metode Quality of Service (QoS) pada jaringan yang padat;, jurnal jaringan computer Universitas Sriwijaya,

3. Rahadi (2010,p.113), "Analisa data kualitatif, Penerbit Andi, Yogyakarta.

4. http://teknologi3G.

blogspot.com/2017/11/19,

dewobandwidth. zip 